\title{
Efeitos de Níveis Crescentes de Fibra em Detergente Neutro na Dieta sobre a Fermentação Ruminal em Bubalinos e Bovinos ${ }^{1}$
}

\author{
Nedilse Helena de Souza ${ }^{2}$, Raul Franzolin ${ }^{3}$, Paulo Henrique Mazza Rodrigues ${ }^{4}$, \\ Rodrigo de Almeida Scoton 5
}

\begin{abstract}
RESUMO - Quatro bubalinos e quatro bovinos adultos com fístulas ruminais foram utilizados com o objetivo de estudar os efeitos de diferentes níveis de fibra em detergente neutro na dieta sobre as características de fermentação ruminal. Foram avaliados concentração de amônia, produção de ácidos graxos voláteis (acético, propiônico e butírico) e pH do líquido ruminal. Os animais foram delineados em dois quadrados latinos (4x4) com arranjo fatorial 4x2, sendo quatro níveis crescentes de FDN na MS (54, 60, 66 e 72\%) e duas espécies (bubalinos e bovinos). Cada subperíodo compreendeu 29 dias, sendo 13 de adaptação. Observou-se efeito da espécie sobre o pH ruminal, em que os bubalinos apresentaram valor médio $(6,78)$ superior ao dos bovinos $(6,58)$. Houve efeito da interação tempo x espécie, na concentração de amônia do líquido ruminal somente após 2 horas da alimentação da manhã, em que os bubalinos obtiveram média de $31,76 \mathrm{mg} \%$ e os bovinos, de $27,74 \mathrm{mg} \%$. Os bubalinos mostraram menores valores de concentração média de ácidos graxos voláteis, ácido acético, ácido propiônico e ácido butírico $(69,94 ; 51,31$; e $6,12 \mathrm{mM})$ que os bovinos $(77,96 ; 56,72$; e 8,01 mM). Não houve diferença na concentração de ácido propiônico e na relação acético:propiônico, não sofrendo influência de nenhum dos parâmetros principais analisados.
\end{abstract}

Palavras-chave: bubalino, bovino, fermentação ruminal, fibra em detergente neutro

\section{Effects of the Increasing Levels of Neutral Detergent Fiber in the Diet on the Ruminal Fermentation in Water Buffaloes and Cattle}

\begin{abstract}
Four buffaloes and four cattle rumen fistulated were used to study the effects of different levels of neutral detergent fiber in the diet on the rumen fermentation characteristics. Ammonia concentration, volatile fatty acids (VFA) production (acetic acid, propionic acid and butyric acid) and $\mathrm{pH}$ in the ruminal fluid were evaluated. The animals were allotted to two latin square experimental design (4x4) in a 4x2 factorial arrangement with four increasing levels of NDF in the DM (54, 60, 66 and 72\%) and two animal species (buffaloes and cattle). Four twenty-nine days subperiods were used, with 13 days for diet adaptation. It was observed the effect of species on the ruminal $\mathrm{pH}$, with average of 6.78 for buffaloes and of 6.58 for cattle. There was an interaction time x species effect for rumen ammonia concentration only at 2 hours after feeding, and buffaloes showed mean of $31.76 \mathrm{mg} \%$ and cattle $27.74 \mathrm{mg} \%$. Buffaloes showed lower VFA average concentration of acetic acid, propionic acid and butyric acid, (69.94, 51.31 and 6.12 mM), than the cattle (77.96, 56.72 and $8.01 \mathrm{mM})$, respectively. There was no difference in the propionic acid concentration and acetic: propionic ratio, which was not influenced by anyone of the mainly determined characteristics.
\end{abstract}

Key Words: cattle, buffalo, ruminal fermentation, neutral detergent fiber

\section{Introdução}

Os bubalinos diferem de taurinos e zebuínos em vários aspectos, como os hábitos comportamentais e as características de interação com o meio ambiente.

As funções metabólicas desses animais não estão bem descritas como nos bovinos, havendo carência de informação sobre o comportamento digestivo. Estudos que forneçam essas informações são impor- tantes para o desenvolvimento de um manejo adequado, principalmente quanto ao fornecimento de dietas ideais ou alternativas.

A administração experimental de dietas pobres em proteína e à base de volumosos de baixa qualidade tem levado a melhor desempenho dos bubalinos. Isto sugere a adequação desses animais às condições brasileiras, já que a criação do rebanho de corte é realizada, em grande parte, sob áreas de vegetação nativa composta de alto

\footnotetext{
1 Parte da tese de Mestrado do primeiro autor - projeto financiado pela FAPESP.

2 Estudante de Mestrado em Qualidade e Produtividade Animal - FZEA/USP. E.mail: nhs@netsite.com.br

3 Professor Associado do Departamento de Zootecnia - FZEA/USP. E.mail: rfranzol@usp.br

4 Professor Assistente do Departamento de Nutrição e Produção Animal - FMVZ/USP. E.mail: pmazza@usp.br

5 Estudante de Graduação em Zootecnia - FZEA/USP - Bolsista de IC - FAPESP.
} 
teor de fibra e baixa porcentagem de proteína.

A fermentação e síntese de nutrientes no rúmen são realizadas pelos diferentes microrganismos existentes no ambiente ruminal (bactérias, protozoários ciliados e fungos). FRANZOLIN (1994) citou trabalhos sobre metabolismo ruminal de bubalinos e bovinos, nos quais os bubalinos têm apresentado maiores concentrações de ácidos graxos voláteis (acético, propiônico e butírico) e de amônia no líquido ruminal que os bovinos, em diversos sistemas de alimentação. Infelizmente, esses trabalhos têm sido realizados, em sua grande maioria, nos países asiáticos com alimentação típica, diferindo das condições existentes no Brasil.

LUNDRI e RAZDAN (1981) observaram que o pH ruminal não sofreu alteração em bubalinos e bovinos alimentados com quatro níveis de proteína na ração, correspondendo a 100, 80, 60 e 40\% da exigência em proteína digestível para a manutenção, e o pH nunca ultrapassou a 7,0, sendo maior no rúmen dos bubalinos.

O objetivo do trabalho foi verificar os efeitos da inclusão de quatro níveis crescentes de FDN na dieta em duas espécies de ruminantes domésticos (bubalinos e bovinos) e as possíveis relações interespecíficas sobre parâmetros ruminais de produção de ácidos graxos voláteis (acético, butírico e propiônico), concentração de amônia e pH.

\section{Material e Métodos}

O experimento foi realizado na Faculdade de Zootecnia e Engenharia de Alimentos, localizada no Campus de Pirassununga da USP.

Foram utilizados quatro bubalinos da raça Mediterrâneo e quatro bovinos da raça Holandês, castrados, com peso vivo médio inicial de 580 e $410 \mathrm{~kg}$, respectivamente, todos fistulados no rúmen com cânulas de látex de $10 \mathrm{~cm}$ de diâmetro. Antes do início do experimento, os animais receberam suplementação de complexo vitamínico A, D e E, por meio de injeção intramuscular, e foram tratados com vermífugo e vacinados contra febre aftosa.

O experimento teve quatro subperíodos de 29 dias cada, sendo 13 dias de adaptação dos animais à dieta.

Quatro dietas foram formuladas para serem isoprotéicas e conterem quatro níveis crescentes de FDN (54, 60, 66 e 72\% na MS). O concentrado foi constituído de milho em grãos moídos, farelo de soja, farelo de trigo, óleo de soja e uréia. O único volumoso utilizado foi o feno de coastcross (Cynodon dactylon), o qual teve os fardos desintegrados, resultando em fragmentos de, aproximadamente, $10 \mathrm{~cm}$ de comprimento. A quantidade de ração fornecida foi calculada em função do consumo durante o período de adaptação, para que não existissem sobras. Amostras dos ingredientes das rações (menos o óleo de soja e a uréia) foram realizadas semanalmente, durante todo o período experimental, e analisadas no laboratório para a determinação da MS, PB e FDN.

Na Tabela 1, encontram-se a composição das rações e as análises dos ingredientes utilizados.

A quantidade total diária de alimentos foi fornecida em duas refeições, metade no período da manhã ( 8 h) e a outra no período da tarde $(16 \mathrm{~h})$. Uma mistura de sal mineral foi fornecida ad libitum no período da manhã, antes da alimentação.

As amostras de líquido ruminal, de aproximadamente $500 \mathrm{~mL}$, foram coletadas via fístula, às $0,2,4$, 8 e 12 h após o arraçoamento matinal ( 8 h), com auxílio de uma bomba de vácuo manual. Para mensuração do $\mathrm{pH}$, entretanto, foi realizada uma coleta adicional às 24 horas. A amostra referente a $0 \mathrm{~h}$ foi realizada antes que os animais recebessem a primeira alimentação. A segunda refeição foi oferecida depois da amostragem das $8 \mathrm{~h}$.

As determinações dos AGV no líquido ruminal foram realizadas por meio de cromatografia gasosa, segundo método preconizado por ERWIN et al. (1961). Para tal, foi utilizado o cromatógrafo a gás (aparelho VARIAN modelo STAR $3.600 \mathrm{cx}$ ) equipado com coluna de metal.

A determinação do nitrogênio amoniacal $\left(\mathrm{N}-\mathrm{NH}_{3}\right)$ foi realizada por colorimetria, segundo método proposto por KULASEK (1972), e adaptado por FOLDAGER (1977).

Foi utilizado o delineamento experimental em dois quadrados latinos 4x4 (PIMENTEL GOMES, 1985), com arranjo fatorial $4 \times 2$, correspondendo aos níveis de $\operatorname{FDN}(54,60,66$ e 72\% na MS) e às espécies (bubalina e bovina).

Os dados obtidos foram analisados por meio do programa computacional Statistical Analysis System (SAS Institute Inc., 1985). As análises referentes aos dados de AGV, pH e concentrações de amônia no líquido ruminal separaram como fontes de variação os efeitos dos níveis de FDN (N), das espécies (E), da interação entre esses fatores $(\mathrm{E} \times \mathrm{N}) \mathrm{e}$, ainda, o efeito das linhas (subperíodos) e das colunas (animais). Quando a interação entre os fatores níveis de FDN e a espécie foi significativa $(\mathrm{P}<0,05)$, foram testados os efeitos dos níveis de FDN dentro das espécies e viceversa, por meio do uso de contrastes ortogonais. 
Rev. bras. zootec.

Tabela 1 - Composição das rações e teores de matéria seca, proteína e fibra em detergente neutro das rações e dos ingredientes

Table 1 - Composition of the diets and contents of dry matter, crude protein and neutral detergent fiber of the diets and ingredients

\begin{tabular}{|c|c|c|c|c|c|c|c|}
\hline \multirow{4}{*}{$\begin{array}{l}\text { Ingredientes } \\
\text { Ingredient }\end{array}$} & \multirow{2}{*}{\multicolumn{4}{|c|}{$\begin{array}{c}\text { Ração } \\
\text { Diet }\end{array}$}} & \multirow{4}{*}{$\begin{array}{l}\text { MS } \\
D M\end{array}$} & \multirow{4}{*}{$\begin{array}{l}\mathrm{PB} \\
C P\end{array}$} & \multirow{4}{*}{$\begin{array}{l}\text { FDN } \\
N D F\end{array}$} \\
\hline & & & & & & & \\
\hline & \multirow[t]{2}{*}{54} & \multirow[t]{2}{*}{60} & \multirow[t]{2}{*}{66} & \multirow[t]{2}{*}{72} & & & \\
\hline & & & & & & & \\
\hline Feno de coastcross $(\%)$ & 48,00 & 58,00 & 71,00 & 88,00 & 89,26 & 6,16 & 82,84 \\
\hline Coastcross hay & & & & & & & \\
\hline Farelo de trigo $(\%)$ & 34,00 & 26,50 & 15,50 & - & 87,68 & 18,58 & 36,65 \\
\hline Wheat meal & & & & & & & \\
\hline Milho em grãos moídos (\%) & 15,50 & 10,50 & 5,00 & 2,00 & 87,78 & 10,90 & 9,17 \\
\hline Ground corn & & & & & & & \\
\hline Farelo de soja (\%) & 2,50 & 5,00 & 8,50 & 10,00 & 87,26 & 52,43 & 18,25 \\
\hline Soybean meal & & & & & & & \\
\hline Óleo de soja (mL) & - & - & - & 150 & - & - & - \\
\hline Soybean oil & & & & & & & \\
\hline Uréia $(g)$ & - & - & - & 40 & - & - & - \\
\hline Urea & & & & & & & \\
\hline $\mathrm{MS}(D M), \%$ & 87,12 & 88,61 & 88,82 & 89,02 & & & \\
\hline $\mathrm{PB}(C P), \%$ & 12,30 & 12,30 & 12,22 & 14,59 & & & \\
\hline FDN $(N D F), \%$ & 53,70 & 59,24 & 65,76 & 73,60 & & & \\
\hline
\end{tabular}

Quando estas não foram significativas, utilizou-se a probabilidade dos efeitos principais. Foi utilizado também o fator medidas repetidas no tempo, referentes aos diversos momentos de coleta entre as refeições. Esta análise foi realizada utilizado-se o comando "repeated" gerado pelo procedimento do módulo GLM (PROC GLM do SAS). Somente quando as interações entre tempo e efeitos principais ( $\mathrm{N}$ ou $\mathrm{E}$ ) ou entre tempo e interação ( $\mathrm{E} \mathrm{N}$ ) foram significativas é que a análise foi realizada por tempo. Quando estas interações com o tempo não ocorreram, mas foram observadas interações entre os efeitos principais, a separação por contrastes foi baseada na média de todos os tempos de amostragem.

\section{Resultados e Discussão}

Os valores do $\mathrm{pH}$ ruminal obtidos nos diversos tempos de amostragem encontram-se na Tabela 2.

A interação tempo $x$ níveis de FDN apresentou desvio da equação quadrática $(\mathrm{P}<0,05)$, nos tempos 2, 4 e 12 horas após o arraçoamento. $\mathrm{O}$ efeito de tempo de amostragem sobre o $\mathrm{pH}$ ruminal foi altamente significativo $(\mathrm{P}=0,0001)$.

As curvas dos valores médios de $\mathrm{pH}$ do líquido ruminal em búfalos e bovinos podem ser vistas na Figura 1.

Foi observado efeito significativo $(\mathrm{P}<0,01)$ da espécie sobre o $\mathrm{pH}$ ruminal, sendo a média dos bubalinos e bovinos de, respectivamente, 6,78 e 6,58. $\mathrm{O}$ pH médio do líquido ruminal dos bovinos mostrouse inferior ao valor de 6,7 recomendado por MOULD

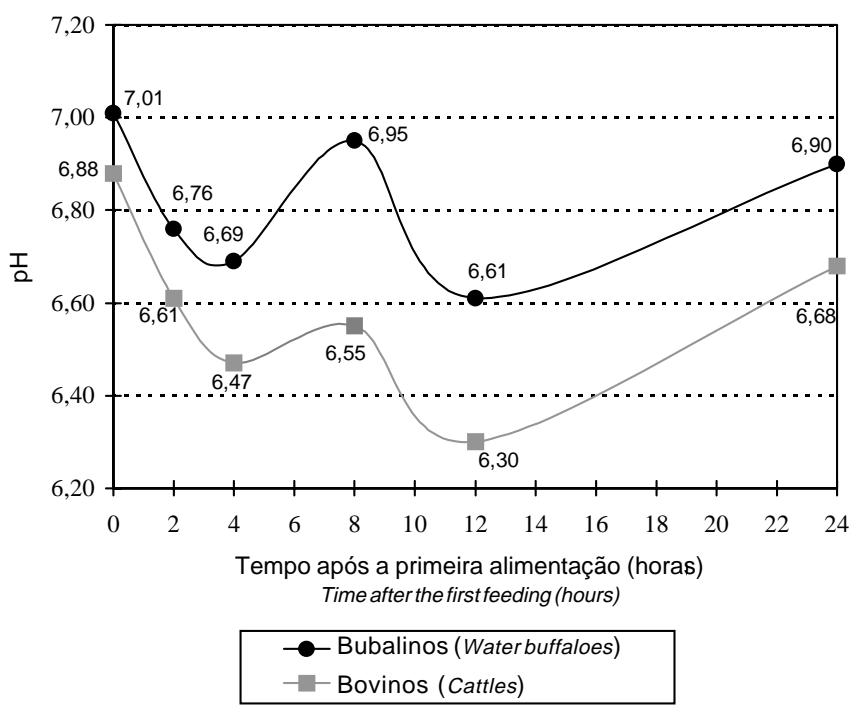

Figura 1 - Curvas de $\mathrm{pH}$ médio do líquido ruminal em bubalinos e bovinos alimentados com quatro níveis de FDN na ração.

Figure 1 - Curves of average ruminal pH in buffaloes and cattle fed four dietary NDF levels. 
Tabela 2 - Efeitos dos níveis de FDN e da espécie sobre o pH do líquido ruminal Table 2 - Effects of NDF levels and of species on the ruminal pH

\begin{tabular}{|c|c|c|c|c|c|c|c|c|c|c|c|c|c|c|c|}
\hline \multirow{3}{*}{$\begin{array}{l}\mathrm{N}^{1} \\
\text { Tempo (horas) } \\
\text { Time (hours) } \\
\end{array}$} & \multicolumn{4}{|c|}{$\begin{array}{c}\text { Bubalinos } \\
\text { Water buffaloes }\end{array}$} & \multicolumn{4}{|c|}{$\begin{array}{c}\text { Bovinos } \\
\text { Cattles }\end{array}$} & \multirow{3}{*}{$\begin{array}{l}\text { Média } \\
\text { Mean }\end{array}$} & \multirow{3}{*}{$\mathrm{CV}$} & \multirow{3}{*}{$\begin{array}{l}\text { Espécie } \\
\text { Species }\end{array}$} & \multicolumn{3}{|c|}{$\begin{array}{c}\text { Probabilidades } \\
\text { Probability }\end{array}$} & \multirow{3}{*}{$\begin{array}{r}\mathrm{E} \times \mathrm{N} \\
S \times L\end{array}$} \\
\hline & \multirow[t]{2}{*}{54} & \multirow[t]{2}{*}{60} & \multirow[t]{2}{*}{66} & \multirow[t]{2}{*}{72} & \multirow[t]{2}{*}{54} & \multirow[t]{2}{*}{60} & \multirow[t]{2}{*}{66} & \multirow[t]{2}{*}{$\overline{72}$} & & & & & $\begin{array}{l}\text { Nível } \\
\text { Level }\end{array}$ & & \\
\hline & & & & & & & & & & & & $\mathrm{L}$ & Q & $\mathrm{D}$ & \\
\hline 0 & 6,96 & 7,10 & 7,02 & 6,97 & 7,00 & 6,80 & 6,84 & 6,86 & 6,94 & 2,91 & - & 0,7448 & 0,7533 & 0,6433 & - \\
\hline 2 & 6,63 & 6,74 & 6,80 & 6,88 & 6,60 & 6,48 & 6,63 & 6,71 & 6,68 & 2,90 & - & 0,6013 & 0,4478 & 0,0106 & - \\
\hline 4 & 6,53 & 6,65 & 6,78 & 6,78 & 6,43 & 6,30 & 6,58 & 6,55 & 6,58 & 4,08 & - & 0,1982 & 0,9018 & 0,0269 & - \\
\hline 8 & 6,37 & 6,84 & 6,76 & 6,83 & 6,53 & 6,42 & 6,63 & 6,62 & 6,62 & 3,83 & - & 0,1091 & 0,2270 & 0,1736 & - \\
\hline 12 & 6,52 & 6,52 & 6,67 & 6,73 & 6,19 & 6,26 & 6,33 & 6,43 & 6,46 & 4,74 & - & 0,4471 & 0,4181 & 0,0389 & - \\
\hline$\underline{24}$ & 6,87 & 7,02 & 6,95 & 6,77 & 6,74 & 6,61 & 6,62 & 6,76 & 6,79 & 3,11 & - & 0,9496 & 0,9578 & 0,6040 & - \\
\hline $\begin{array}{l}\text { Média } \\
\text { Mean }\end{array}$ & 6,64 & 6,81 & 6,83 & 6,83 & 6,58 & 6,48 & 6,60 & 6,66 & 6,68 & 4,28 & 0,0007 & 0,3163 & 0,5580 & 0,0786 & 0,2643 \\
\hline
\end{tabular}

Efeito de tempo significativo $(P=0,0001)$ (Effect significant on time $[P=0.0001])$.

Efeito da interação tempo $x$ espécie $(P=0,3200)$ (Effect of interaction on time $x$ specie $[P=0.3200]$ ).

Efeito da interação tempo $x$ nível $(P=0,1034)$ (Effect of interaction on time $x$ level $[P=0.1034]$ ).

tempo $x$ nível : linear $(P=0,3366)$ (time $\times$ level: linear $[P=0.3366])$.

:

tempo $\times$ nível : desvio da quadrática $(P=0,0215)$ (time $\times$ level :Quadract deviation $[P=0.0215]$ ).

Efeito da interaccão tempo $x$ espécie $x$ nível $(P=0,6179)$ (Effect of interaction on time $x$ specie $x$ level $[P=0.6179]$ ).

${ }^{1} \mathrm{~N}=$ Nível de FDN $(\% \mathrm{MS})\left({ }^{1} \mathrm{~N}=\mathrm{NDF}\right.$ level $[\%$ DM] $)$ 
Rev. bras. zootec.

et al. (1983), para não haver queda na taxa de degradação da fibra.

As medidas de $\mathrm{pH}$ do líquido ruminal executadas por FRANZOLIN NETO et al. (1990), em bubalinos e bovinos alimentados com mesma dieta contendo só volumoso, mostraram que o $\mathrm{pH}$ foi significativamente $(\mathrm{P}<0,01)$ maior na espécie bubalina $(\mathrm{pH}=6,28)$ que na bovina $(\mathrm{pH}=5,98)$, corroborando o presente experimento. Entretanto, NOGUEIRA FILHO (1995) não observou diferença significativa para o $\mathrm{pH}$ médio em bubalinos e bovinos, em um período de 24 horas, com amostragem a cada 2 horas após o arraçoamento.

Constam da Tabela 3 e Figura 2 as concentrações de nitrogênio amoniacal no líquido ruminal. A média geral, em ambas as espécies, foi de 21,46 mg\%, considerando todo o período diário de amostragem, o qual foi compreendido pelo tempo antes da primeira refeição até 12 horas após. O efeito de tempo para a concentração de amônia apresentou-se altamente significativo $(\mathrm{P}=0,0001)$, sendo esta extrema variabilidade comum em ruminantes alimentados de forma intermitente (MEHRES et al., 1977). Outros fatores podem ainda influenciar este parâmetro, como local de amostragem no rúmen, período de estocagem da amostra, conservante ácido utilizado, método de determinação e tipo da dieta (WOHLT et al., 1976).

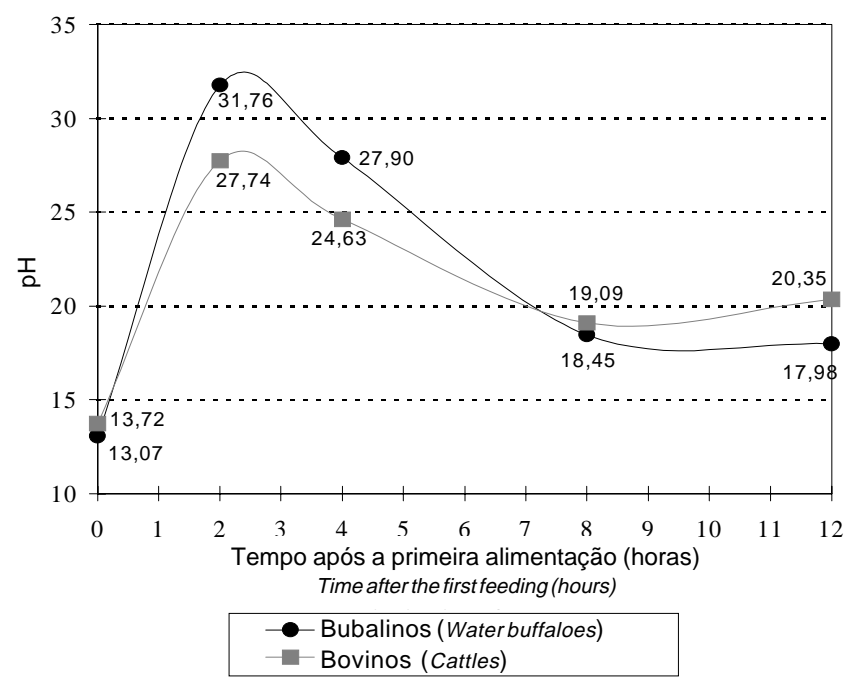

Figura 2 - Concentrações médias de amônia (mg\%) no líquido ruminal, em diversas horas após a primeira refeição, em bubalinos e bovinos alimentados com quatro níveis de FDN na ração.

Figure 2 - Average ruminal ammonia concentration (mg\%), at different post feeding hours, in buffaloes and in the cattle fed four dietary NDF levels.

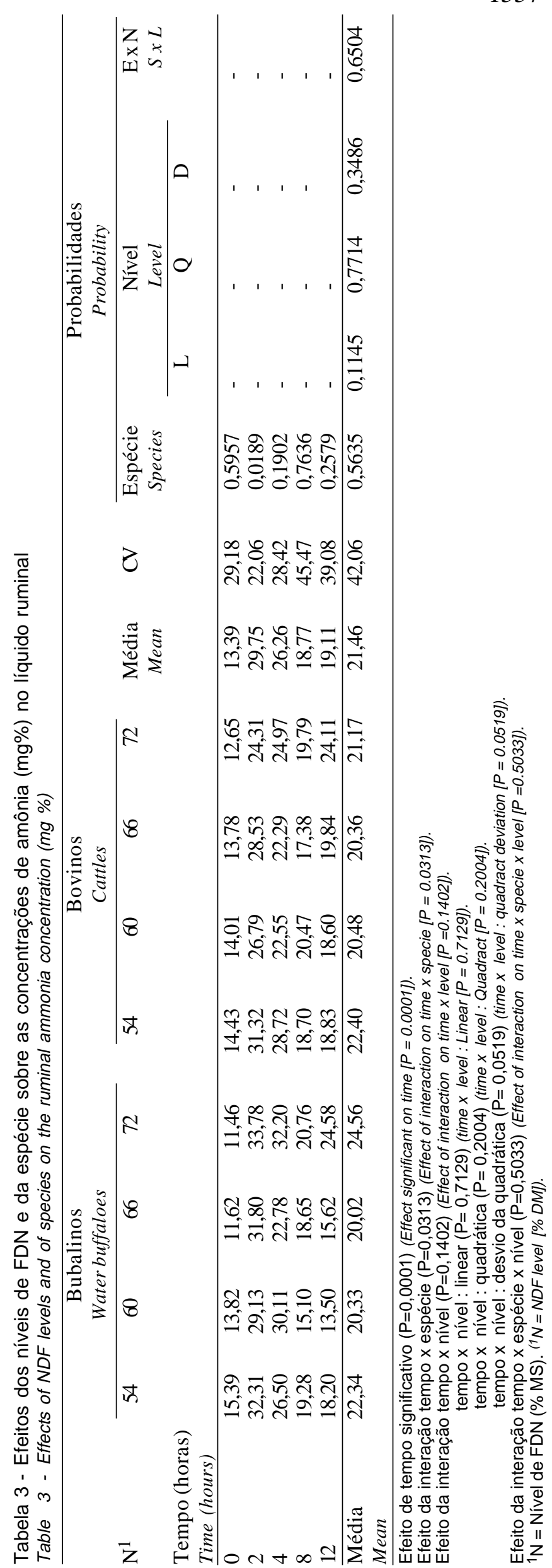


Os valores médios de amônia encontrados foram maiores que os recomendados por SATTER e SLYTER (1974), PRESTON e LENG (1987) e PISULEWSKI et al. (1981), correspondentes a 5,0; 8,0 ; e $9,6 \mathrm{mg} \%$, respectivamente, para o máximo crescimento microbiano, mas abaixo dos $24 \mathrm{mg} \%$ recomendados por MEHRES et al. (1977) para máximo desaparecimento do substrato, embora esses autores tenham proposto não ser necessário manter, de forma constante, altas concentrações de amônia no líquido ruminal.

Não foram observados efeitos dos níveis de FDN sobre a concentração ruminal de amônia $(\mathrm{P}>0,05)$.

Houve efeito da interação tempo $\mathrm{x}$ espécie ( $\mathrm{P}=0,0313)$, mostrando elevação de $12,66 \%$ nas médias da concentração de amônia do líquido ruminal dos bubalinos $(31,76 \mathrm{mg} \%)$ em relação aos bovinos $(27,74 \mathrm{mg} \%)$, em 2 horas após o arraçoamento matinal. Isso corrobora os achados de PALIWAL e SAGAR (1990) de que o pico de amônia em duas horas após a alimentação, em quatro dietas (14\% PB) é maior para os bubalinos, o que indica maior atividade proteolítica no rúmen de bubalinos que no de bovinos, fato confirmado por BHATIA et al. (1992).

ZANETTI et al. (1995), utilizando uma ração composta de feno de coastcross, fubá de milho e farelo de algodão com $9,91 \%$ PB, coletaram líquido ruminal em 2, 4, 6 e 8 horas após a alimentação da manhã e verificaram que os bubalinos apresentaram

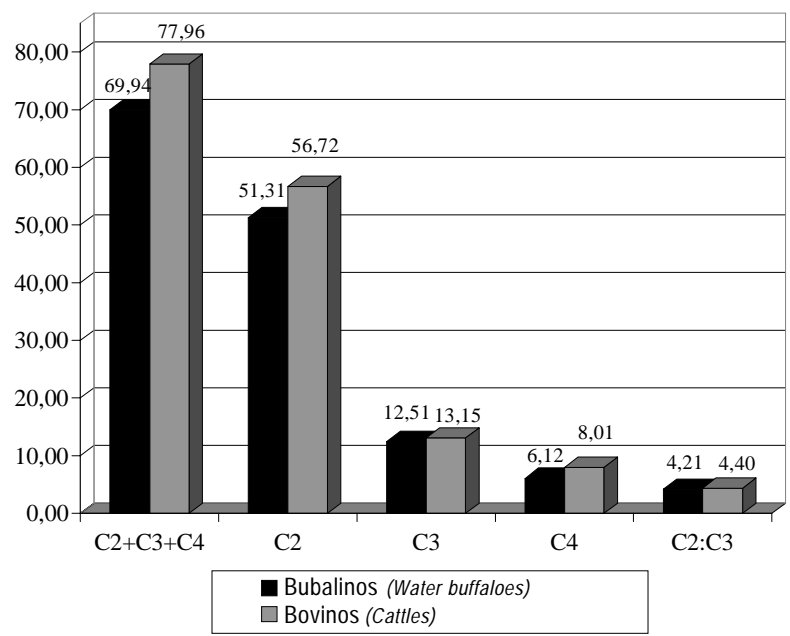

Figura 3 - Concentrações médias de ácidos graxos voláteis, ácido acético, ácido propiônico e ácido butírico e da relação acético:propiônico no líquido ruminal $(\mathrm{mM})$, em diversas horas após a primeira refeição, em bubalinos e bovinos.

Figure 3 - Average concentration of volatile fatty acid, acetic acid, propionic acid, butyric acid, acetic:propionic ratio in the ruminal fluid $(\mathrm{mM})$, at different post feeding hours, in buffaloes and in the cattle.

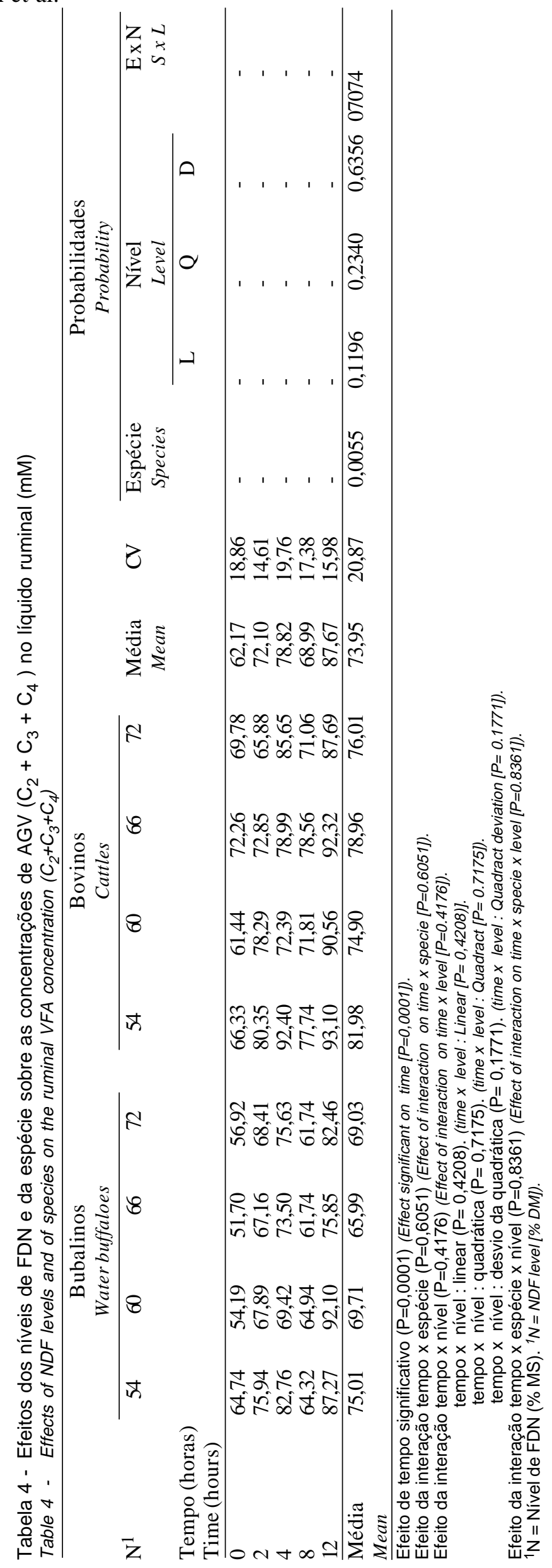


Tabela 5 - Efeitos dos níveis de FDN e da espécie sobre as concentrações de ácido acético (mM) no líquido ruminal Table 5 - Effects of NDF levels and of species on the ruminal acetic acid concentration (mM)

\begin{tabular}{|c|c|c|c|c|c|c|c|c|c|c|c|c|c|c|c|}
\hline \multirow[b]{2}{*}{$\mathrm{N}^{1}$} & \multicolumn{4}{|c|}{$\begin{array}{c}\text { Bubalinos } \\
\text { Water buffaloes }\end{array}$} & \multicolumn{4}{|c|}{$\begin{array}{l}\text { Bovinos } \\
\text { Cattles }\end{array}$} & \multirow{3}{*}{$\begin{array}{l}\text { Média } \\
\text { Mean }\end{array}$} & \multirow{3}{*}{$\mathrm{CV}$} & \multicolumn{5}{|c|}{$\begin{array}{c}\text { Probabilidades } \\
\text { Probability }\end{array}$} \\
\hline & 54 & 60 & 66 & 72 & 54 & 60 & 66 & 72 & & & \multirow[t]{2}{*}{$\begin{array}{l}\text { Espécie } \\
\text { Species }\end{array}$} & \multicolumn{3}{|c|}{$\begin{array}{l}\text { Nível } \\
\text { Level }\end{array}$} & \multirow[t]{2}{*}{$\begin{array}{r}\mathrm{E} \times \mathrm{N} \\
S \times L\end{array}$} \\
\hline $\begin{array}{l}\text { Tempo (horas) } \\
\text { Time (hours) }\end{array}$ & & & & & & & & & & & & $\mathrm{L}$ & Q & $\mathrm{D}$ & \\
\hline 0 & 49,56 & 40,12 & 40,05 & 42,19 & 49,96 & 45,22 & 54,28 & 52,47 & 46,86 & 18,53 & - & - & - & - & - \\
\hline 2 & 54,80 & 49,34 & 49,45 & 49,93 & 58,21 & 56,22 & 53,22 & 47,65 & 52,35 & 13,74 & - & - & - & - & - \\
\hline 4 & 60,34 & 49,81 & 54,08 & 55,16 & 66,94 & 52,26 & 57,70 & 62,29 & 57,32 & 19,05 & - & - & - & - & - \\
\hline 8 & 46,87 & 47,67 & 45,30 & 45,25 & 56,60 & 51,78 & 57,73 & 51,42 & 50,33 & 16,16 & - & - & - & - & - \\
\hline$\underline{12}$ & 63,78 & 66,14 & 55,00 & 59,40 & 65,84 & 64,71 & 66,48 & 63,35 & 63,08 & 14,84 & - & - & - & - & - \\
\hline $\begin{array}{l}\text { Média } \\
\text { Mean }\end{array}$ & 55,05 & 50,61 & 48,77 & 50,82 & 59,51 & 54,04 & 57,88 & 55,44 & 54,03 & 19,43 & 0,0065 & 0,1300 & 0,2552 & 0,3367 & 0,6775 \\
\hline
\end{tabular}

Efeito de tempo significativo $(P=0,0001)$. (Effect of interaction on time $x$ specie $[P=0.7383]$ ).

Efeito da interação tempo $x$ espécie $(P=0,7383)$ (Effect of interaction on time $x$ level $[P=0.3603]$ ).

Efeito da interação tempo $x$ nível $(P=0,3603)$. (time $x$ level : Linear $[P=0.6116]$ ).

tempo $x$ nível : linear $(P=0,6116)$ (time $\times$ level : quadract $[P=0.1592]$ ).

tempo $\times$ nível : quadrática $(P=0,1592)$ (time $x$ level : quadract deviation $[P=0.4405]$ ).

tempo $x$ nível : desvio da quadrática $(P=0,4405)$. (Effect of interaction on time $x$ specie $\times$ level $[P=0.8743])$.

Efeito da interação tempo $x$ espécie $\times$ nível $(P=0,8743)$ (Effect significant on time $[P=0.0001]$ ).

${ }^{1} \mathrm{~N}=$ Nível de FDN (\% MS). ( ${ }^{1} \mathrm{~N}=\mathrm{NDF}$ level [\% DM] $)$. 
Tabela 6 - Efeitos dos níveis de FDN e da espécie sobre as concentrações de ácido propiônico (mM) no líquido ruminal Table 6 - Effects of NDF levels and of species on the ruminal propionic acid concentration (mM)

\begin{tabular}{|c|c|c|c|c|c|c|c|c|c|c|c|c|c|c|c|}
\hline \multirow[b]{2}{*}{$\mathrm{N}^{1}$} & \multicolumn{4}{|c|}{$\begin{array}{c}\text { Bubalinos } \\
\text { Water buffaloes }\end{array}$} & \multicolumn{4}{|c|}{$\begin{array}{l}\text { Bovinos } \\
\text { Cattles }\end{array}$} & \multirow{3}{*}{$\begin{array}{l}\text { Média } \\
\text { Mean }\end{array}$} & \multirow{3}{*}{$\mathrm{CV}$} & \multicolumn{5}{|c|}{$\begin{array}{c}\text { Probabilidades } \\
\text { Probability }\end{array}$} \\
\hline & 54 & 60 & 66 & 72 & 54 & 60 & 66 & 72 & & & $\begin{array}{l}\text { Espécie } \\
\text { Species }\end{array}$ & & $\begin{array}{l}\text { Nível } \\
\text { Level }\end{array}$ & & $\begin{array}{r}\mathrm{E} \times \mathrm{N} \\
S \times L\end{array}$ \\
\hline $\begin{array}{l}\text { Tempo (horas) } \\
\text { Time (hours) }\end{array}$ & & & & & & & & & & & & $\mathrm{L}$ & $Q$ & $\mathrm{D}$ & \\
\hline 0 & 49,56 & 40,12 & 40,05 & 42,19 & 49,96 & 45,22 & 54,28 & 52,47 & 46,86 & 18,53 & - & - & - & - & - \\
\hline 0 & 9,95 & 10,21 & 8,28 & 8,96 & 10,16 & 10,05 & 11,59 & 11,16 & 10,04 & 24,81 & - & - & - & - & - \\
\hline 2 & 14,28 & 12,64 & 12,34 & 12,42 & 13,69 & 13,43 & 11,86 & 11,32 & 12,75 & 17,57 & - & - & - & - & - \\
\hline 4 & 14,74 & 13,15 & 13,07 & 13,43 & 15,71 & 12,23 & 12,63 & 14,98 & 13,70 & 22,05 & - & - & - & - & - \\
\hline 8 & 11,40 & 11,46 & 10,72 & 10,57 & 13,30 & 11,98 & 12,86 & 12,04 & 11,79 & 22,31 & - & - & - & - & - \\
\hline 12 & 15,94 & 17,41 & 14,00 & 15,31 & 17,25 & 15,96 & 15,95 & 15,45 & 15,91 & 19,47 & - & - & - & - & - \\
\hline Média & 13,26 & 12,97 & 11,68 & 12,14 & 14,02 & 12,73 & 12,97 & 12,88 & 12,83 & 25,89 & 0,2188 & 0,0828 & 0,3472 & 0,8502 & 0,7032 \\
\hline
\end{tabular}

Efeito de tempo significativo ( $\mathrm{P}=0,0001)$ (Effect significant on time $[P=0,0001])$.

Efeito da interacão tempo $x$ espécie $(P=0,4625)$ Effect of interaction on time $x$ specie $[P=0.4625]$ ).

Efeito da interação tempo $x$ nível $(P=0,8910)$ (Effect of interaction on time $x$ level $[P=0.8910]$ ).

tempo $x$ nível : linear $(P=0,7687)$. (time $\times$ level : Linear $[P=0.7687])$.

tempo $x$ nível : quadrática $(P=0,6140)$. (time $x$ level : Quadract $[P=0.6140]$ ).

tempo $\times$ nível : desvio da quadrática $(P=0,8132)$. (time $x$ level : Quadract deviation $[P=0.8132]$.

Efeito da interação tempo $x$ espécie $x$ nível $(P=0,9447)$

(Effect of interaction on time $x$ specie $x$ level $[P=0.9447]$ ).

$\mathrm{N}=$ Nível de FDN (\% MS) ( ${ }^{1} \mathrm{~N}=\mathrm{NDF}$ level [\% DM]). 
Tabela 7 - Efeitos dos níveis de FDN e da espécie sobre as concentrações de ácido butírico (mM) no líquido ruminal Table 7 - Effects of NDF levels and of species on the ruminal butyric acid concentration (mM)

\begin{tabular}{|c|c|c|c|c|c|c|c|c|c|c|c|c|c|c|c|}
\hline \multirow[b]{2}{*}{$\mathrm{N}^{1}$} & \multicolumn{4}{|c|}{$\begin{array}{c}\text { Bubalinos } \\
\text { Water buffaloes }\end{array}$} & \multicolumn{4}{|c|}{$\begin{array}{c}\text { Bovinos } \\
\text { Cattles }\end{array}$} & \multirow{4}{*}{$\begin{array}{l}\text { Média } \\
\text { Mean }\end{array}$} & \multirow{4}{*}{$\mathrm{CV}$} & \multicolumn{5}{|c|}{$\begin{array}{c}\text { Probabilidades } \\
\text { Probability }\end{array}$} \\
\hline & 54 & 60 & 66 & 72 & 54 & 60 & 66 & 72 & & & $\begin{array}{l}\text { Espécie } \\
\text { Species }\end{array}$ & & $\begin{array}{l}\text { Nível } \\
\text { Level }\end{array}$ & & $\begin{array}{l}E \times N \\
S \times L\end{array}$ \\
\hline Tempo (horas) & & & & & & & & & & & & $\mathrm{L}$ & Q & $\mathrm{D}$ & \\
\hline Time (hours) & & & & & & & & & & & & & & & \\
\hline 0 & 49,56 & 40,12 & 40,05 & 42,19 & 49,96 & 45,22 & 54,28 & 52,47 & 46,86 & 18,53 & - & - & - & - & - \\
\hline 0 & 5,33 & 3,86 & 3,38 & 4,81 & 6,21 & 6,17 & 6,39 & 6,15 & 5,29 & 34,52 & - & - & - & - & - \\
\hline 2 & 6,78 & 5,92 & 5,38 & 6,07 & 8,45 & 8,64 & 7,77 & 6,91 & 6,70 & 31,29 & - & - & - & - & - \\
\hline 4 & 7,68 & 6,47 & 6,35 & 7,04 & 9,75 & 7,90 & 7,96 & 8,88 & 7,75 & 33,43 & - & - & - & - & - \\
\hline 8 & 6,05 & 5,81 & 5,72 & 5,91 & 7,84 & 8,05 & 8,03 & 7,60 & 6,88 & 32,38 & - & - & - & - & - \\
\hline 12 & 7,56 & 8,54 & 6,14 & 7,75 & 10,02 & 8,86 & 9,89 & 8,90 & 8,52 & 27,36 & - & - & - & - & - \\
\hline $\begin{array}{l}\text { Média } \\
\text { Mean }\end{array}$ & 6,70 & 6,12 & 5,35 & 6,32 & 8,45 & 7,87 & 8,01 & 7,69 & 7,06 & 34,85 & 0,0278 & 0,5678 & 0,7742 & 0,9883 & 0,9306 \\
\hline
\end{tabular}

Efeito de tempo significativo ( $P=0,0001)$ (Effect significant on time $[P=0.0001])$.

Efeito da interação tempo $x$ espécie $x$ nível $(P=0,7443)$ (Effect of interaction on time $x$ specie $x$ level $[P=0.7443]$ ).

Efeito da interação tempo $x$ espécie $(P=0,7541)$ (Effect of interaction on time $x$ specie $[P=0.7541]$ ).

Efeito da interação tempo $x$ nível $(P=0,8727)$ (Effect of interaction on time $x$ level $[P=0.8727]$ ).

tempo $\times$ nível : Linear $(P=0,6540)$ (time $\times$ level : Linear $[P=0,6540])$.
tempo $\times$ nível : Quadrática $(P=0,6610)$ (time $\times$ level : Quadract $[P=0.6610]$ ).
tempo x nível : desvio da quadrática $(P=0,8656)$ (time $\times$ level : Quadract deviation $[P=0.8656]$ ). 
Tabela 8 - Efeitos dos níveis de FDN e da espécie sobre as relações acético:propiônico no líquido ruminal

Table 8 - Effects of NDF levels and of species on the ruminal acetic:propionic ratio

\begin{tabular}{|c|c|c|c|c|c|c|c|c|c|c|c|c|c|c|c|}
\hline \multirow[b]{2}{*}{$\mathrm{N}^{1}$} & \multicolumn{4}{|c|}{$\begin{array}{c}\text { Bubalinos } \\
\text { Water buffaloes }\end{array}$} & \multicolumn{4}{|c|}{$\begin{array}{c}\text { Bovinos } \\
\text { Cattles }\end{array}$} & \multirow{3}{*}{$\begin{array}{l}\text { Média } \\
\text { Mean }\end{array}$} & \multirow{3}{*}{$\mathrm{CV}$} & \multicolumn{5}{|c|}{$\begin{array}{c}\text { Probabilidades } \\
\text { Probability }\end{array}$} \\
\hline & 54 & 60 & 66 & 72 & 54 & 60 & 66 & 72 & & & $\begin{array}{l}\text { Espécie } \\
\text { Species }\end{array}$ & & $\begin{array}{l}\text { Nível } \\
\text { Level }\end{array}$ & & $\begin{array}{r}\mathrm{E} \times \mathrm{N} \\
S \times L\end{array}$ \\
\hline $\begin{array}{l}\text { Tempo (horas) } \\
\text { Time (hours) }\end{array}$ & & & & & & & & & & & & $\mathrm{L}$ & Q & $\mathrm{D}$ & \\
\hline 0 & 49,56 & 40,12 & 40,05 & 42,19 & 49,96 & 45,22 & 54,28 & 52,47 & 46,86 & 18,53 & - & - & - & - & - \\
\hline 0 & 4,98 & 4,39 & 4,85 & 4,86 & 4,95 & 4,57 & 4,70 & 4,77 & 4,76 & 12,38 & - & - & - & - & - \\
\hline 2 & 3,96 & 3,90 & 4,01 & 4,10 & 4,34 & 4,26 & 4,52 & 4,21 & 4,16 & 12,39 & - & - & - & - & - \\
\hline 4 & 4,13 & 3,79 & 4,20 & 4,17 & 4,39 & 4,32 & 4,59 & 4,31 & 4,24 & 11,61 & - & - & - & - & - \\
\hline 8 & 4,22 & 4,21 & 4,42 & 4,32 & 4,47 & 4,42 & 4,54 & 4,27 & 4,36 & 14,11 & - & - & - & - & - \\
\hline$\underline{12}$ & 4,06 & 3,80 & 3,96 & 3,91 & 3,95 & 4,08 & 4,26 & 4,12 & 4,02 & 9,72 & - & - & - & - & - \\
\hline $\begin{array}{l}\text { Média } \\
\text { Mean }\end{array}$ & 4,27 & 4,02 & 4,29 & 4,27 & 4,42 & 4,33 & 4,52 & 4,34 & 4,31 & 13,41 & 0,1339 & 0,9182 & 0,2728 & 0,4175 & 0,9001 \\
\hline
\end{tabular}

Efeito de tempo significativo ( $\mathrm{P}=0,0001)$ (Effect significant on time $[\mathrm{P}=0.0001])$.

Efeito da interacão tempo $x$ espécie $\times$ nível $(P=0,9901)$ (Effect of interaction on time $x$ specie $\times$ level $[P=0.9901]$ ).

Efeito da interação tempo $x$ espécie $(P=0,2579)$ (Effect of interaction on time $x$ specie $[P=0.2579]$ ).

Efeito da interação tempo $\times$ nível $(P=0,9197)$ (Effect of interaction on time $\times$ level $[P=0.9197]$ ).

tempo $\times$ nível $(P=0,9197)($ Effect of interaction on time $\times$ level $[P=0.9197])$.
tempo $\times$ nível : linear $(P=0,4623)$. (time $\times$ level $:$ Linear $[P=0.4623])$.
tempo $\times$ nível : quadrática $(P=0,9127)$ (time $\times$ level : Quadract $[P=0.9127])$.

tempo $x$ nível : desvio da quadrática $(P=0,8904)$. (time $x$ level : Quadract deviation $[P=0.8904]$ ).

tempo $x$ nível : desvio da quadr.
${ }^{1} \mathrm{~N}=$ Nível de FDN (\% MS). $\left({ }^{1} \mathrm{~N}=\mathrm{NDF}\right.$ level $\left.[\% \mathrm{DM}]\right)$. 
maiores valores de amônia $(17,18 \mathrm{mg} / 100 \mathrm{~mL})$ que os bovinos $(11,93 \mathrm{mg} / 100 \mathrm{~mL})$. Não houve interação tempo x espécie e o nível de amônia ruminal aumentou significativamente nas primeiras duas horas após a alimentação, diminuindo a seguir.

RAJ KUMAR et al. (1993) usaram quatro diferentes fontes de FDN nas dietas (14\%PB) e não observaram diferença significativa $(\mathrm{P}>0,05)$ para a concentração de $\mathrm{NH}_{3}$, AGV e coeficiente de digestibilidade da MS, PB, FDN, FDA e constituintes da parede celular em relação a bubalinos e bovinos. Os mesmos resultados foram apresentados por KENNEDY et al. (1992) para a concentração de $\mathrm{NH}_{3}$ e AGV.

Os valores de $\mathrm{AGV}\left(\mathrm{C}_{2}+\mathrm{C}_{3}+\mathrm{C}_{4}\right)$, as concentrações de ácidos acético $\left(\mathrm{C}_{2}\right)$, propiônico $\left(\mathrm{C}_{3}\right)$ e butírico $\left(\mathrm{C}_{4}\right)$ erelações acético:propiônico encontram-se, respectivamente, nas Tabelas 4, 5, 6, 7 e 8 e na Figura 3.

Não foram observados efeitos dos níveis de FDN sobre a concentração de $\mathrm{AGV}\left(\mathrm{C}_{2}+\mathrm{C}_{3}+\mathrm{C}_{4}\right)$ para as concentrações de $\mathrm{C}_{2}, \mathrm{C}_{3}$ e $\mathrm{C}_{4}$ e para a relação acético:propiônico dosados no experimento $(\mathrm{P}>0,05)$. Porém, observou-se o efeito do tempo altamente significativo $(\mathrm{P}=0,0001)$ para estes parâmetros.

Foi observado efeito significativo $(\mathrm{P}<0,01)$ da espécie sobre a concentração de $\mathrm{AGV}\left(\mathrm{C}_{2}+\mathrm{C}_{3}+\right.$ $\mathrm{C}_{4}$ ) com a média dos bubalinos $(69,94 \mathrm{mM})$ e bovinos (77,96 mM), produzindo diferença de 10,29\% maior para os bovinos. Menor concentração de AGV no líquido ruminal de bubalinos foi também relatada por MORAN et al. (1983) e KENNEDY (1995), podendo ser atribuída à maior passagem de AGV no fluído ruminal para o omaso desta espécie. Este fato poderia ser explicado, também, por maior absorção de $\mathrm{AGV}$ pelas paredes do rúmen dos bubalinos.

Para as concentrações individuais de ácido acético e de ácido butírico, os bovinos (médias de 56,72 e $8,01 \mathrm{mM}$ ) apresentaram aumento de 9,54 e $23,60 \%$, respectivamente, sobre os bubalinos (médias de 51,31 e 6,12 mM). Em contraste, VALADARES FILHO et al. (1990), analisando AGV totais e ácidos acético, propiônico e butírico, observaram que houve efeito $(\mathrm{P}<0,05)$ de grupo genético somente para a concentração de ácido butírico, sendo que os búfalos apresentaram maior concentração que os holandeses (2,34 vs. 1,27 mmoles/100 mL), não encontrando explicação para tais resultados.

A concentração de ácido propiônico e a relação acético:propiônico não sofreram influência de nenhum parâmetro principal analisado, concordando com PRASAD e PRADHAN (1990), que, testando volumosos de baixa qualidade com vários níveis de concentrados sobre o metabolismo de bovinos, bubalinos e ovinos, observaram que a concentração de ácido propiônico não sofreu diferença significativa $(\mathrm{P}>0,05)$ para espécies e tratamentos.

\section{Conclusões}

Os diferentes níveis de FDN na ração não influenciaram a produção ruminal de amônia e AGV tanto em bubalinos como em bovinos. Os bovinos apresentaram maiores concentrações de AGV, ácidos acético e butírico e os bubalinos apresentaram maiores valores médios diários de pH e de amônia após duas horas da alimentação.

\section{Referências Bibliográficas}

BHATIA, S.K., PRADHAN, K., SINGH, R. et al. 1992. Effect of feeding wheat straw and oat on rumen microbial and enzymatic activities in cattle and buffalo. Ind. J. Anim. Sci., 62(4):364-368.

FOLDAGER, J. Protein requirement and non-protein nitrogen for high producing cow in early lactation. Ph.D. Thesis, East Lasing - Michigan State University, 1977.

FRANZOLIN NETO, R., NOGUEIRA FILHO, J.C.M., ZANETTI, M.A. Avaliação dos protozoários ciliados no rúmen de búfalo e bovino. In: CONGRESSO MUNDIAL DE BUIATRIA, 14, Salvador, BA, 1990. Anais... Salvador, 1990, p.258-262.

FRANZOLIN, R. Feeding efficiency: a comparison between buffalo and cattle. 1994. Buffalo J., suppl. 2, p.39-50.

KENNEDY, P.M., BONIFACE, A.N., LIANG, Z.J. et al. 1992. Intake and digestion in swamp buffaloes and cattle. 2 . The comparative response to urea supplemented in animals fed tropical grasses. J. Agric. Sci., 119:(2):243-254.

KENNEDY, P.M. 1995. Intake and digestion in swamp buffaloes and cattle. 3. Comparisons with four forage diets, and with rice straw supplemented with energy and protein. J. Agric. Sci., 124:265-275.

KULASEK, G.A. 1972. A micromethod for determination of urea in plasma, whole blood and blood cells using urease and phenol reagent. Pol. Arch. Wet., 15(4):801-810.

LUNDRI, R.S., RAZDAN, M.N. 1981. Effect of variable amount of dietary nitrogen on $\mathrm{pH}, \mathrm{VFA}$ and total and particulate nitrogen in the rumen of cow and buffaloes. Indian J. Dairy Sci., 34(3):272-277.

MEHRES, A.Z., ØRSKOV, E.R., McDONALD, I. 1977. Rates fermentation in relation to ammonia concentration. The British J. Nut., 38(3):437-443.

MORAN, J.B., SATOTO, K.B., DAWSON, J.E. 1983. The utilization of rice straw fed to Zebu cattle and swamp buffalo as influenced by alkali treatment and Leucaena supplementation. Austr. J. Agric. Res., 34:481-492.

NOGUEIRA FILHO, J.C.M. Estudo da degradabilidade in situ e de protozoários ciliados com zebuínos da raça Nelore (Bos taurus indicus) e búfalos (Bubalus bubalis) submetidos a dietas com volumosos e concentrados. Pirassununga, SP: 
FZEA, 1995. 144p. Tese (Livre Docência) - Faculdade de Zootecnia e Engenharia de Alimentos/Universidade de São Paulo, 1995.

PALIWAL, V.K., SAGAR, V. 1990. Effect of dietary fiber protein on rumen microbial fermentation in cattle and buffalo. Ind. J. Anim. Sci., 60(1):66-70.

PIMENTEL GOMES, F. 1985. Curso de estatística experimental. Piracicaba, SP: ESALQ. 467p.

PISULEWSKI, P.M., OKORIE, A.U., BUTTERY, P.J. et al. 1981. Ammonia concentration and protein synthesis in the rumen. J. Sci. Food Agric., 32(8):759-766.

PRASAD, D., PRADHAN, K. 1990. Effect of feeding poor quality roughage combined with varying levels of concentrate mixture on rumen metabolic profiles in cattle, buffalo and sheep. Ind. J. Anim. Sci., 60(7):853-860.

PRESTON, T.R., LENG, R.A. 1987. Ruminant production systems. Queensland, Austrália. 245p.

RAJ KUMAR, SANGWAN, D.C., BHATIA, S.K. et al. 1993. Intraruminal metabolism and nutrient digestion in cattle and buffalo fed low-grade roughages supplemented with protein sources. Ind. J. Anim. Sci., 63(5):561-565.

SAS Institute Inc. SAS User's guide: statistics. Ver. 5 ed., SAS Inst., Cary, NC, 1985.
SATTER, L.D., SLYTER, L.L. 1974. Effect of ammonia concentration of rumen microbial protein production in vitro. Br J. Nutr., 32:199-203.

VALADARES FILHO, S.C., COELHO DA SILVA, J.F., LEÃO, M.I. et al. 1990. Digestibilidade in vitro e alguns parâmetros de fermentação ruminal medidos em novilhos holandeses, Nelores e búfalos mestiços alimentados com ração purificada. R. Soc. Bras. de Zootec., 19(5):441-449.

WOHLT, J.E., CLARK, J.H., BLAISDELL, F.S. 1976. Effect of sampling location, time and method of concentration of ammonia nitrogen in the rumen. J. Dairy Sci., 59(3):459-464.

ZANETTI, M.A., NOGUEIRA FILHO, J.C., OLIVEIRA, M.E.M. et al. Níveis de amônia ruminal em bovinos da raça Nelore e em búfalos da raça Mediterrâneo. In: REUNIÃO ANUAL DA SOCIEDADE BRASILEIRA DE ZOOTECNIA, 32, Brasília, 1995. Anais ... Brasília: SBZ, 1995. p.351-352.

Recebido em: 13/10/99

Aceito em: 02/04/00 